\title{
A New Phase of Women in Rama Mehta's: Inside the Haveli and The Western Educated Hindu Women
}

\author{
Afsana Bano ${ }^{a}$, Dr. Nidhi Bhatnagar ${ }^{b}$ \\ ${ }^{a}$ Research Scholar, School of Arts and Humanities, Sangam University, Bhilwara, India \\ E-mail: aazammansuri123@gmail.com \\ ${ }^{\mathrm{b}}$ Associate Professor, School of Arts and Humanities, Sangam University, Bhilwara, India \\ E-mail: nidhibhl@gmail.com
}

Article History: Received: 10 November 2020; Revised 12 January 2021 Accepted: 27 January 2021; Published online: 5 April 2021

\begin{abstract}
This particular work reveals the voyage of Geeta in the cross-cultural context and also the perception of society towards a daughter-in-law with reference to both the works of Rama Mehta. The concepts like child marriage and education are focused here, while influencing the life of the protagonist directly or indirectly. She expresses the psychological and emotional struggle of a woman's search for self identity. In this work I have tried to introduce a new phase of feminism with the works of Rama Mehta and proved that modern women are not dominated and subordinated by any force of society, as she possess the power to take her own decision and can stand on their own capabilities. Now the women are empowered and independent.
\end{abstract}

Keywords: modern women, education, marriage, child marriage, self identity

\section{Introduction}

Feminism is the belief that all people should be treated equally in legal, economic and social arenas- regardless of gender, religion, sexual orientation, ethnicity and other similar pre-dominant identifying traits.(Choudhary 623)

Rama Mehta being a sociologist has also studied some educated Indian women at the time when they got stuck between the ancient pangs of tradition and independence of modernity. Her works Inside the Haveli and The Western Educated Hindu Women depicts the women characters of different generations and ideologies at different positions. As each generation brings new thoughts and ideas, here in Inside the Haveli it is clearly indicated that modernity is knocking at the door of the "Jivan Nivas". Here Haveli is a symbol of tradition and the culture pursued by its constituents.

"Indian patriarchal society has converted woman more into a myth, a dream, or a fantasy rather than an identity as a human being." (Kumari 88)

Inside the Haveli has many female characters, among them Geeta is the protagonist. Her character in the beginning portrays the suffering, disappointments and the frustrations which accompany her after her arrival in Jivan Niwas but later she develops herself as a strong woman who opposes the decisions of the aristocrats of the Haveli. Geeta reflects the life of Rama Mehta as they both are from an educated background and married to a narrow minded, traditional bound family in Udaipur. They both sacrifice their distinguished career after their marriage leaving hardly any choice for them. As Rama Mehta says in her work:

"After marriage a woman became a member of another family and had to adjust to new ways if she wanted to be loved and respected. She had no choice but to accept a polygamous basis of marriage." (Mehta 17)

Ajitkumar Sinha has quoted that:

"Women in India are, by and large victim of social, economic and political exploitation". (Sinha 27)

The protagonist in the novel "Inside the Haveli" is a newly married girl who is in the beginning was discontented with the new environment at her in-law's place. She has conflict with the male dominated and conformist society but as the time passes her intellectual compel her to become a symbol of revolution. This work presents a close depiction of an organization which is surviving since feudal era and is a disclosure of attitudes towards female figure and their position in a certain fragment of Indian society.

"Women in general have the higher incidence of the experiences of trauma which affects the very core of their self."'(Geeta 193) 
Sociologist and feminist Rama Mehta is well known for her novel "Inside the Haveli". This particular work exhibits her struggle of self identity and the achievement of the same. She has forced to resign her post when she was married to an aristocrat with deep rooted traditional family of Udaipur. Like Rama Mehta, Geeta goes with the situations in her life. She throughout the novel swings from present to past and back again to present, from her life in Bombay to Udaipur. She sometimes even feels nostalgic assuming her in Bombay, where she was a democratic girl, studied with boys and had pleasured moments.

\section{Education as a tool to shatter the ties:}

It is the changing phase in woman's existence, where she is all surrounded by the adversities of the world around and yet making efforts to flourish her colors. Geeta, a well educated girl finds it complicated to adjust in the totally different environment of Udaipur. But through her intellectual and efforts she carves her own destiny by changing the perception of the associates of Haveli about the importance of education for even a daughter of servant and also abolishes the practice of child marriage which was prevalent in the society through the ages.

"Women under the patriarchal pressure and control were subjected to much more brunt's and social ostracism. They were discriminated and were biased in lien of their sex" (Chikara 190)

As it can be observed that somehow men is changing its perception towards the education of women, which is in return gently producing a feeling optimism in women. Though this independence is merely for the cause of men's solace but it somehow widens the gateway of liberty for women, and it is up to her to formulate best out of it.

"The incentive to continue with their studies was given by their husbands. This encouragement was given not so much because the men wanted educated companion, but because they felt that with some education their women would be better equipped to cope with their new life." (Mehta 23)

Now a day's women are carving their existence in all possible arenas. With time their contribution and position in society is also modifying itself, but no doubt it is because of their own efforts and indulgence.

After marriage, Geeta is searching and struggling for her own identity but with the phase of time she eventually represents herself as a rebel against the unjust norms of the Haveli. Her education occupied in Bombay nodded her every single moment in the Haveli. She initially adjusts herself in the adverse norms of the Haveli while not only observing the norms of the Haveli, but also spreading her influence on it.

We can trace her rebel at the time some situations occur in the Haveli. The first one is when "Sita" the daughter of her maid was not allowed to get formal education by joining school but Geeta managed so for her. The idea for sending Sita School was aroused in her by her daughter Vijay, when she once while going to school asked her mother out of curiosity.

“If I can go to school, why can’t Sita? Vijay insisted. Petulantly, holding on to Sita's cold hand.” (Mehta 95)

As Sita was a child of a servant, moreover a girl, she was not even allowed to cross the gates of Haveli without permission. The servants themselves had not thought of educating their children. Pari the senior maid replies to Geeta on the idea of sending Sita to school for her formal education.

"Pari stared open mouthed at the young mistress as if someone had stuck the maid on head... Pari pulled her together and said decisively, 'Binnijiji, Sita is a child of a servant. She cannot go to school." (Mehta 98)

The mentality of servants towards the education of their children is clearly visible in these lines. They always regarded their children as servants only, who in future will serve the Haveli as their parents are doing now. But in spite of all criticism and disapproval Geeta somehow managed to send Sita for schooling with the recommendation of her father-in-law whose orders are never questioned by anyone in the Haveli.

Apart from this, Geeta had also started classes for the servants and their children of Haveli and neighborhood in order to teach them the basics of education. While starting the classes also she has to overcome many obstacles. Most of the residents of the Haveli are against it, as they are afraid that it may lead to alter our customs and traditions which was their ancestry. And they are not at all ready to compromise on this. But, in spite of all circumstances against her, she succeeded in bringing this reform in the Haveli. She added sewing classes for whom it was impossible to learn alphabets. Her father-in-law always encouraged her.

Bhagwat Singhji was interested in what Geeta doing and encouraged her. He had gIven her two sewing machines and had instructed the accountants that "all expenses of the classes would be paid from his personal account." (Mehta 179) 
Education has always remained at secondary position for the society. For a girl the household chores are always occupied the first position and her proposal for marriage was accepted if she is good at it. We can trace in the case of Geeta's daughter Vijay, when she stood first in her class, Kanwarani Sa teased her saying:

"Coming first is all right, Vijay, but you must also learn to cook and sew. Don't become like your mother." (Mehta 153)

The necessity of education is observed by everyone in the Haveli, when Sita got approved by a well known family of a village having four acres of land. For a daughter of servant this was assumed as a golden chance to get married in a well equipped family. Even the mother-in-law of Geeta praised her as she was the one who insisted her and after troublesome conversations sent Sita to school.

Bhagwat Singhji's wife looked at Geeta fondly and said humbly "Binniji you will be blessed, it is all your doing. I am glad you did not listen to us, ignorant women. We could never have arranged a match like this for Sita" (Mehta 187)

Kaki Sa, thanks to Binniji, would you belive it that my maid's daughter is earning a hundred rupee as an ayah in a school? The woman said.(Mehta 179)

Geeta's efforts are acknowledged by every person be it of Haveli or an outsider. She not only opened the path to an improved life for the poor and suppressed but somehow brought reforms to the Haveli which were never seen earlier.

\section{Child Marriage: Curse To Society}

Marriage in Hindu culture is to pursue dharma and arth, it is for ultimate infinity in which souls are united eternally. It is also considered as a protection of girl from the world. Without marriage she can be regarded as unprotected. A woman cannot be imagined without a husband, she has to dependent on a man socially, emotionally and economically also.

The respondents were also brought up to see marriage as an economic and emotional security for women. (Mehta 113)

Child marriage is considered as a curse and an obstacle in the pathway of advancement of a child in the modern society. But in earlier times this act was regarded a beneficial for both parents and child. This ritual is considered sacred and should be carried out by parents as early as possible. Geeta too had to face this traumatic phase her life, when her Thirteen year old daughter Vijay was in school her elders decided to marry her in the most respectful family of Udaipur. This time Geeta had to face the rage of her elders but she was determined not to waste her child with these rotten customs and traditions of the society. She openly opposed and disregarded it.

“No, I can’t have Vijay marry young, times have changed. She must study.” (Mehta 252)

She not only opposed it but also opened a path for all mothers to say in the marriage of their daughter.

As time passes she became the mistress of the Haveli, holding the norms and customs of the Haveli with a new touch of modernity in it. Geeta has taken the initiative to change the system and she succeeded in accomplishing her resolve.

\section{Conclusion}

This work revealed the victory of women with her will power. Geeta here attempts to rupture the patriarchal rules and eventually emerges as a new educated Indian woman by initializing literacy movement inside the Haveli. The protagonist doesn't stop herself until she gets an atmosphere in which there is an end in the steady governance of patriarchy.

\section{Acknowledgement}

I would like to express my gratitude and special thanks towards my guide and mentor Dr. Nidhi Bhatnagar for her constant support and guidance in the compilation of my work.

\section{References}

Mehta, Rama. "Inside the Haveli". Penguin Books India, 1996.

Mehta, Rama. "The Western Educated Hindu Woman”. Asia Publishing house New York,1970.

Chaudhary, Sushila, and Usha Sharma. "Feminism in India and Manju Kapur's Fiction." Strength for Today and Bright Hope for Tomorrow, vol 12, no.1, 2012, pp. 623-631.

Chikara, Mayur."Manju Kapoor's Difficult Daughters A Saga of Feminist Autonomy and Separate Identity" Strength for Today and Bright Hope for Tomorrow, vol 10, no.7, 2010, pp. 189-195. 
Geetha, S. S., and T. Ramakrishnan. "Trauma of Women in Manju Kapur's A Married Woman." A Journal of Composition Theory, vol 8, no.1, 2020, pp. 193-198.

Kumari, Archana. "Interrogating the Patriarchy in Namita Gokhale's God, Graves and Grandmother." International Journal of English Language, Literature and Humanities, vol 3, no. 10, 2015, pp. 88-97.

Sinha, Ajit Kumar. "New Dimensions of Women Empowerment". New Delhi: Deep \& Deep Publications Pvt. Ltd., 2008. 